\title{
Cocaine addiction: treatments and future perspectives
}

\author{
Adição a cocaína: tratamentos e perspectivas futuras
}

Cocaine addiction is a major public health problem that imposes high costs on society, including health problems, lost work productivity, and treatment costs. Cocaine use is widespread worldwide, although it is concentrated in North and South America and Western and Central Europe..$^{1,2}$

Development and dissemination of effective treatments is a major priority in the public health policies of many countries. In recent years, attempts to improve treatment outcomes have generated an increase in research into the efficacy of different therapeutic strategies. The most important international agencies and organizations have established several effective interventions such as the Cognitive Behavioral Therapy, CRA plus vouchers program, Contingency Management and Behavioral Couples Therapy. ${ }^{3,4}$ In addition to psychosocial interventions focused on the user, specific interventions for family members provide the opportunity to explore their situation and explore the interactions between family and user.

A large number of drugs have been tested for treatment of addiction. The most used are antidepressants, mood stabilizers, dopaminergic agonists, stimulants, and precursors of neurotransmitters, and there is a long list of drugs that are still experimental. It is generally considered that pharmacological therapies have to be combined with behavioral strategies to achieve better results. ${ }^{5}$ Reviews of pharmacological treatment of cocaine dependence suggest inconclusive results, including reviews of treatment for crack users. ${ }^{6}$

Despite the progress achieved in recent years in understanding brain and behavioral mechanisms related to cocaine addiction, treatment outcomes remain poor, and it is common for patients to relapse and resume consumption. Current trends in research reflect concerns with obtaining more generalizable scientific evidence and the pursuit of efficacy, and several lines of study emerge: the influence of cognitive and neuropsychological factors in treatment outcomes; ${ }^{7}$ use of new technologies to supplement treatment processes; ${ }^{8}$ combining treatment strategies; ${ }^{9}$ determining the cost of generalization of interventions; ${ }^{10}$ incorporating strategies into post-treatment to reduce the costs of relapses; ${ }^{11}$ and collecting further evidence on some promising procedures so that they can be integrated into more proven treatments, ${ }^{12}$ among others. A new approach focusing on pharmacotherapeutic agents with multiple neurobiochemical objectives and on identifying effective drugs for the specific needs of patients with specific clinical characteristics represents an encouraging change in the design of trials and current pharmacological approaches. ${ }^{13}$

Additionally, research could be directed towards establishing possible relationships between patient characteristics and intervention modalities and their influence on maintaining abstinence and treatment retention. Given the heterogeneity of the population, identifying subgroups of patients according to their characteristics and their needs could help in this task and could also be a response to problems observed in patients who use multiple psychoactive substances.

Traditionally, the efficacy of treatments for cocaine abuse has been demonstrated in specialized research contexts, so it would be appropriate to encourage research in community settings, where the real difficulties that clinicians may encounter when they want to apply a particular type of treatment can best be appreciated. Improving the utility of treatments currently administered 
in clinical settings would result in lower costs and higher patient quality of life. Clinicians and patients expect intervention strategies to be developed and improved.

\section{Emilio Sánchez-Hervás}

Addictive Behaviors Unit of Catarroja, Valencia Regional Health Department, Valencia, Spain.

\section{References}

1. United Nations Office for Drugs and Crime (UNODC). World Drug Report. Vienna: United Nations Publication; 2015.

2. European Monitoring Centre for Drugs and Drug Addiction (EMCDDA). European Drug Report 2015: trends and development. Lisbon: European Union; 2015.

3. National Institute of Health and Clinical Excellence (NICE). CG 51 Drug misuse: psychosocial interventions. London: National Institute of Clinical Excellence; 2007.

4. National Institute on Drug Abuse (NIDA). Principles of drug addiction treatment: a research base-guide. 3rd ed. Bethesda: National Institutes of Health, U.S. Department of Health and Human Services; 2014.

5. Department of Health (DHD). Drug misuse and dependence: UK guidelines on clinical management. London: Department of Health (England), the Scottish Government, Welsh Assembly Government, and Northern Ireland Executive; 2007.

6. Fischer B, Blanken P, Da Silveira D, Gallassi A, Goldner EM, Rehm J, et al. Effectiveness of secondary prevention and treatment interventions for crack-cocaine abuse: a comprehensive narrative overview of English-language studies. Int J Drug Policy. 2015;26:352-63.

7. Kiluk BD, Carroll KM. New developments in behavioral treatments for substance use disorders. Curr Psychiatry Rep. 2013;15:420.

8. Carroll KM, Kiluk MD, Nich C, Gordon MA, Portnoy GA, Marino $D R$, et al. Computer-assisted delivery of cognitive-behavioral therapy: efficacy and durability of cbt4cbt among cocaine- dependent individuals maintained on methadone. Am J Psychiatry. 2014;171:436-44.

9. Petitjean SA, Dürsteler-MacFarland KM, Krokar MC, Strasser J, Mueller SE, Degen B, et al. A randomized, controlled trial of combined cognitive-behavioral therapy plus prize-based contingency management for cocaine dependence. Drug Alcohol Depend. 2014;145:94-100.

10. Shearer J, Tie H, Byford S. Economic evaluations of contingency management in illicit drug misuse programmes: a systematic review. Drug Alcohol Rev. 2015;34:289-98.

11. Blodgett JC, Maisel NC, Fuh IL, Wilbourne PL, Finney JW. How effective is continuing care for substance use disorders? A metaanalytic review. J Subst Abuse Treat. 2014;46:87-97.

12. Grant S, Hempel S, Colaiaco B, Motala A, Shanman RM, Booth $M$, et al. Mindfulness-based relapse prevention for substance use disorders: a systematic review. Santa Monica: National Defense Research Institute, RAND Corporation; 2015.

13. Shorter D, Domingo $C B$, Kosten TR. Emerging drugs for the treatment of cocaine use disorder: a review of neurobiological targets and pharmacotherapy. Expert Opin Emerg Drugs. 2015;20:15-29.

\section{Correspondence:}

Addictive Behaviors Unit of Catarroja

Valencia Regional Health Department

Av. Rambleta, 14, 46470, Catarroja, Valencia, Spain

Tel.: +34961971512, ext. 407033

E-mail: esh455k@gmail.com

Submitted Feb 04 2016, accepted for publication Mar 092016. No conflicts of interest declared concerning the publication of this article.

Financial support: none.

Suggested citation: Sánchez-Hervás E. Cocaine addiction: treatments and future perspectives [letter]. Trends Psychiatry Psychother. $2016 ; 38(4): 242-243$. http://dx.doi.org/10.1590/22376089-2016-0013 